\title{
A EMBRATEL: DA ERA DA INTERVENÇÃO AO TEMPO DA COMPETIÇÃO'
}

\author{
José Eduardo Pereira Filho \\ Universidade Federal do Rio de Janeiro
}

\begin{abstract}
RESUMO
O artigo trata da política brasileira de telecomunicações nos últimos trinta e cinco anos. Enfoca, em especial, o processo de constituição e consolidação da Empresa Brasileira de Telecomunicações (Embratel). Enfatizamos que o processo decisório ocorrido nos anos 60, quando o setor passou por uma profunda mudança institucional e organizacional favorável à atuação direta do Estado, correspondeu ao ideário desenvolvimentista. Retratamos o salto tecnológico promovido pela Embratel ocorrido ao longo das décadas de 60, 70 e 80 por meio da implantação do Sistema Nacional de Telecomunicações, o que possibilitou a ligação do país pelas telecomunicações, internamente e com o exterior. Por fim, analisamos o processo de privatização das telecomunicações ocorrido ao longo da segunda metade dos anos 90, como parte do programa de reforma econômica do Estado brasileiro. Configura-se então um quadro de competição regulada pelo Estado através da Agência Nacional de Telecomunicações (Anatel).
\end{abstract}

PALAVRAS-CHAVE: politica de telecomunicações; desenvolvimentismo; privatização; competição regulada.

\section{INTRODUÇÃO}

O presente artigo tem como objetivo relatar a trajetória da Empresa Brasileira de Telecomunicações (Embratel) ao longo dos seus 35 anos de atividade, associando-a ao cenário histórico da modernização brasileira ocorrida ao longo da segunda metade do século XX. Partimos da análise do contexto sócio-político da criação da estatal e acompanhamos as principais inovações tecnológicas nesse setor, advindas da implantação do Sistema Nacional de Telecomunicações. Reconhecemos que os enormes investimentos governamentais, fruto do projeto desenvolvimentista, possibilitaram que a empresa promovesse um enorme salto tecnológico no setor de telecomunicações, especialmente nos anos 1960 a 1980.

Discutiremos também o processo de privatização da Embratel, ocorrido a partir da segunda metade da década de 90 , quando uma série de fatores - econômicos e políticos - influenciaram a mudança de rumo das telecomunicações e, em particular, da própria companhia estatal.

\footnotetext{
${ }^{1}$ Este artigo é um desdobramento da disseratação de mestrado Reforma do Estado e política de telecomunicações: o impacto das mudanças sobre a Embratel (PEREIRA FILHO, 1997).
}

O argumento central do trabalho é que a criação da Embratel nos anos 60 correspondeu às expectativas econômicas e políticas em favor da atuação direta do Estado em setores estratégicos, como foi e é o caso das telecomunicações. Naquele período, em várias regiões do mundo, o Estado era um ator central na formulação das políticas econômicas e sociais, fosse o regime socialista da URSS, do leste Europeu e da China, ou o Welfare State da Europa ocidental ou, também, o desenvolvimentismo da América Latina.

As demandas favoráveis à privatização da estatal, surgidas a partir do final dos anos 80, obedeceram às transformações em curso na economia mundial, as quais defendiam a saída do Estado de vários setores estratégicos como a energia, os transportes e as telecomunicações.

Nos anos 80 a onda neoliberal representada pelos governos Ronald Reagan nos EUA e Margareth Thatcher na Grã-Bretanha foram importantes marcos para a reorientação das funções dos estados nacionais em nível mundial. Em 1984, a companhia inglesa British Telecom foi a primeira empresa estatal de telecomunicações a ser privatizada na Europa - fato que significou um marco na política mundial de desestatização das companhias do setor. O ideário político-econômico pro- 
movido pelo Consenso de Washington ${ }^{2}$ foi também um importante referencial para promoção da reestruturação do setor. A abertura política e econômica dos países socialistas teve igualmente um importante peso ideológico. Esses acontecimentos, portanto, ancoraram ideologicamente os defensores da ação privada no setor de telecomunicações.

Sob essa perspectiva, portanto, a inauguração da Embratel esteve inserida em um projeto mais amplo planejado pela elite dirigente que colocou o Estado como um ator central e direto no direcionamento da industrialização e modernização da sociedade brasileira. Do mesmo modo, duas décadas depois, nos anos 80, o colapso do modelo desenvolvimentista colocou em xeque o modelo estatal-monopolista do setor. $\mathrm{O}$ atual cenário das telecomunicações sinaliza um quadro de competição regulada pelo governo central, portanto bastante diferente da situação que imperou até a década de 60 do século XX, caracterizada pela atuação indiscriminada de empresas privadas em várias escalas - local, estadual e regional - e com um baixíssimo controle operacional por parte da União.

Buscaremos responder em que medida a empresa respondeu às expectativas apresentadas no momento da sua criação, tais como a meta de interligar os troncos interestaduais e internacionais e a universalização da telefonia. No momento em que foi privatizada e perdeu o monopólio, a empresa conseguiu responder às demandas em favor da ampliação dos serviços de telecomunicações, em especial a telefonia fixa? Esse setor foi um dos mais questionados pela sua baixa qualidade operacional e pela falta de aparelhos no recente debate acerca da reestruturação do setor.

Reconhecemos, portanto, que tratar das ações e políticas promovidas por uma empresa estatal, como é o caso da Embratel, permite-nos compreender concepções mais amplas acerca do processo de industrialização e modernização da sociedade brasileira ocorrido a partir da segunda metade do século XX. Do mesmo modo, por meio deste estu-

\footnotetext{
2 Assim foi chamada a reunião de um grupo de economistas de tendência liberal, realizada em 1989 no Institute for International Economy, em Washington. Seguindo as orientações do FMI e do Banco Mundial, enfatizou-se a necessidade de promoverem-se reformas no campo da desregulamentação do Estado nas economias latinoamericanas, particularmente a promoção da privatização de setores estratégicos e a abertura comercial.
}

do de caso é possível compreender, em especial, como se deu o processo de constituição da Embratel pela via estatal e como ocorreu a sua privatização após 30 anos.

Portanto, reconhecemos que a análise da trajetória da Embratel permite identificar duas orientações centrais do sistema capitalista: a pró-Estado, que perdurou desde a década de 30 até o final dos anos 80 , e a pró-mercado, que tem sido implementada desde a década de 90 .

\section{A TELEFONIA NO BRASIL NOS ANOS 60}

Desde o final do século XIX até a segunda metade dos anos 60 o setor de telefonia brasileiro foi operado por companhias privadas, em grande parte formadas por capitais estrangeiros. Naquela conjuntura existiam cerca de 800 empresas atuando no campo dos serviços telefônicos no Brasil em âmbito regional, incluindo estados e municípios. As principais empresas eram a Companhia Telefônica Nacional (CTN), subsidiária da companhia norte-americana International Telephone Telegraph (ITT), e a Companhia Telefônica Brasileira (CTB), propriedade da empresa canadense Brazilian Traction.

Na década de 60 não havia uma única empresa que cobrisse todo o território nacional. A subsidiária norte-americana atuava nos estados do Rio Grande do Sul e Paraná, enquanto a companhia canadense detinha cerca de $80 \%$ da telefonia do país e operava na região economicamente mais desenvolvida do Brasil, englobando os estados da Guanabara, Rio de Janeiro, Minas Gerais, Espírito Santo e São Paulo. Esse quadro fazia que o setor tivesse um perfil concentrado em duas companhias e fosse, ao mesmo tempo, pulverizado em outras centenas de empresas de caráter municipal, estadual e regional.

A Constituição de 1946 deu à União a incumbência de explorar diretamente ou mediante concessão os serviços de telefonia interestaduais e internacionais, enquanto os serviços no âmbito local e estadual ficavam sob a responsabilidade dos municípios e estados. Na realidade, o papel do governo central era basicamente normativo e de supervisão das atividades, enquanto as instâncias regionais tinham o papel efetivo na regulamentação da telefonia em seus respectivos territórios. Essa situação era colocada como um dos principais entraves para a implantação das políticas de integração do país de uma forma centralizada e global para o setor. 
Diante desse quadro surgiu uma grande controvérsia acerca do modelo que o país deveria adotar para resolver as dificuldades de um sistema fragmentado, altamente concentrado de telefonia e para atender uma grande demanda por telefones e novas tecnologias em telecomunicações que estavam surgindo. A iniciativa privada era acusada de não ter capacidade financeira para promover a expansão tecnológica necessária para atualizar o sistema operacional e ligá-lo ao restante do mundo.
O excessivo número de empresas, interagindo nas escalas municipal, estadual e regional, era igualmente visto como um problema para a formação de um sistema integrado de telecomunicações.

O Brasil encontrava-se na metade do século $\mathrm{XX}$ entre as nações capitalistas com menor densidade telefônica (1,4 por 100 habitantes). O país ficava atrás da Argentina (5,99 telefones por 100 habitantes), do Uruguai (5,01 telefones por 100 ), e do Chile (2,25 por 100) (Tabela I).

Tabela 1 - Telefonia em vários países (1960-1961)

\begin{tabular}{|c|c|c|c|}
\hline País & Telefones por 100 habitantes & País & Telefones por 100 habitantes \\
\hline EUA & 38 & Alemanha Ocidental & 9,6 \\
\hline Suécia & 35 & Áustria & 8,2 \\
\hline Canadá & 29 & França & 7,2 \\
\hline Suíça & 28,2 & Itália & 5,99 \\
\hline Nova Zelândia & 27,4 & Argentina & 5,01 \\
\hline Dinamarca & 22 & Uruguai & 4 \\
\hline Austrália & 20 & Espanha & 4 \\
\hline Grã Bretanha & 14,5 & Japão & 2,25 \\
\hline Países Baixos & 12 & Chile & 1,6 \\
\hline Finlândia & 12 & União Soviética & 1,4 \\
\hline Bélgica & 11,2 & Brasil & \\
\hline
\end{tabular}

Fonte: Telebrasil, (fev.1961; mar.1961; abr.1961), Diário de Notícias, (08.dez.1960).

Na realidade, o déficit de linhas telefônicas, a defasagem tecnológica do setor, a falta de interconectividade do sistema e valor das tarifas consistiam nos principais obstáculos no campo operacional à atuação da telefonia privada em território nacional.

Nos campos político e ideológico, o ambiente internacional da Guerra Fria e, internamente, o embate entre os partidários da continuidade do modelo privado e o grupo favorável à atuação direta do Estado na telefonia, contribuíram para o debate em torno da reforma do setor de telecomunicações. Os defensores da continuidade do sistema privatista - as empresas privadas - acusavam os segmentos nacionalistas e de esquerda que eram favoráveis à ação direta do Estado de violarem os princípios da livre empresa e da propriedade privada, associando-os, consequentemente, ao socialismo soviético. Do outro lado do debate, os partidários do modelo estatal denunciavam que as companhias estrangeiras estavam apenas preocupadas com o lucro imediato e a serviço do imperialismo norte-americano, desconsiderando, assim, as questões de caráter nacional como a segurança e a integração do país. Havia também que reco- nhecer a existência de uma demanda nos centros urbanos para a expansão do serviço de telefonia, cada vez mais considerada um bem público a quem todos deveriam ter acesso. Nesse momento ocorria também uma enorme mudança tecnológica no setor, com o advento da comunicação via satélite, e emergia com força a área tecnológica das telecomunicações.

Tornou-se então cada vez mais consensual que a iniciativa privada não dispunha do volume de investimento necessário para realizar esse salto tecnológico, queixando-se na época de falta de recursos e das baixas tarifas. Coube assim ao Estado o papel de agente modernizador das telecomunicações. Nos anos 60 criaram-se uma série de conselhos pelos governos Juscelino Kubitscheck, Jânio Quadros e João Goulart para formular uma nova política para o setor, a partir das metas desenvolvimentistas. Nessas comissões estavam presentes os militares, alguns governadores de estado (Leonel Brizola e Carlos Lacerda) ${ }^{3}$ e os

3 O Governador do Rio Grande do Sul, Leonel Brizola, criou a Companhia Rio-Grandense de Telefonia, e o 
representantes das empresas privadas (por meio da Federação das Associações das Empresas de Telecomunicações do Brasil). Na ocasião a imprensa deu bastante visibilidade ao debate (Correio da Manhã, 21.fev.1962; 02.mar.1962; Jornal do Brasil, 27.fev.1962; O Globo, 13.mar.1962; O Estado de São Paulo, 14.mar.1962).

Após intensas negociações no Congresso Nacional, deu-se o primeiro passo rumo à centralização e à estatização da telefonia brasileira. A criação do Código Brasileiro de Telecomunicações ${ }^{4}$ (CBT) em 1963 representou uma verdadeira mudança de rumo nas diretrizes do setor de telefonia e serviços afins.

Por meio da nova legislação inaugurou-se uma política de telecomunicações monopolista nas mãos da União. Esta ganhou a competência de explorar diretamente os serviços em nível nacional e internacional. Os estados e territórios tiveram a incumbência de explorar diretamente ou através de concessões a telefonia intermunicipal. A mesma regra foi mantida para os municípios em sua esfera de atuação.

O novo ordenamento legal autorizou o poder Executivo a criar uma empresa pública autônoma para explorar os serviços interestaduais e internacionais, a Empresa Brasileira de Telecomunicações (Embratel). O Sistema Nacional de Telecomunicações deveria formar um complexo de troncos e redes através dos quais se operariam os seguintes serviços: telefonia, telegrafia, difusão de sons e imagens, transmissão de dados, fac-simile, telecomando e radiodeterminação.

Embora a concepção inicial de um projeto de telecomunicações comandado pelo Estado tenha surgido e tomado a forma de lei no governo João Goulart, a crise política do período impediu que o projeto se viabilizasse naquela conjuntura. Somente com o regime militar é que as telecomunicações tornaram-se uma meta estratégica do Estado. Com a tomada do poder pelos militares em 1964, ocorreu um reforço da Doutrina de Segurança Nacional e as telecomunicações passaram a ser, mais enfa-

Governador da Guanabara, Carlos Lacerda, buscou solucionar a falta de telefones no Rio de Janeiro, tentando criar uma companhia telefônica estadual.

4 O CBT foi criado pela Lei n. 4 177, de 27 de junho de 1962, e regulamentado pelo Decreto n. 52 026, de 20 de maio de 1963. ticamente, uma questão estratégica para a soberania e a segurança nacionais. Em 1965 os militares centralizaram a política de telecomunicações e inauguraram a Embratel como parte de um projeto maior de implantar o Sistema Nacional de Telecomunicações. Em 1967 o Decreto-Lei n. 162 transferiu para a União o poder de os municípios explorarem os serviços de telefonia. Nesse mesmo ano, como parte de uma ampla reforma administrativa do novo regime, criou-se o Ministério das Comunicações (Decreto-Lei n. 200, de 15 de fevereiro de 1967). Juntamente com o novo órgão foram criadas as empresas estaduais de telecomunicações - as "Teles". Em 1972 criou-se uma holding para o setor - a Telebrás (por meio do Decreto n. 70914 de 1972) $)^{5}$ - que incorporou as teles estaduais e a Embratel (ver Organograma adiante). Ficava assim estruturada a base organizacional e institucional para a expansão e modernização das telecomunicações, com a Embratel à frente desse projeto. Nessa estrutura das telecomunicações, o setor privado saía da prestação de serviços, ficando apenas no segmento da indústria de componentes e de equipamentos para telecomunicações.

A inauguração da Telebrás e do Ministério das Comunicações representou a etapa final da centralização da política de telecomunicações nas mãos do Estado. Ao Ministério das Comunicações coube a função normativa, enquanto a Telebrás consolidar-se-ia como o órgão executor da nova diretriz. A reestruturação da política das telecomunicações pôs fim às inúmeras concessionárias espalhadas pelo território nacional e possibilitou a viabilização de um sistema abrangente e ágil.

A seguir analisaremos a implantação do Sistema Nacional de Telecomunicação e as operações da Embratel a partir de meados dos anos 60 .

\section{A IMPLANTAÇÃO DO SISTEMA NACIO- NAL DE TELECOMUNICAÇÕES E OPAPEL DA EMBRATEL (1965-1998)}

\footnotetext{
5 Em 1972 criou-se a Telebrás, a holding do setor à qual a Embratel passava a vincular-se agora como subsidiária de economia mista. Na posição de holding, a Telebrás abarcou também as empresas estaduais ("Teles"), agora subsidiárias. Nessa estrutura de empresa vinculada à Telebrás a Embratel passou a ter a seguinte composição acionária: a Telebrás era a acionista majoritária, com 50,21\% das ações, e a União ficava com outra fatia grande, de $48,24 \%$. O Banco do Brasil ficou com 0,54\%, o BNDE com 0,34\%, a Companhia Vale do Rio Doce com $0,22 \%$, a Petrobrás $0,22 \%$ e a Eletrobrás $0,11 \%$.
} 
A criação da Embratel em 16 de setembro de 1965 marcou a retirada da iniciativa privada dos serviços de telefonia interestadual e internacional. Já no seu primeiro ano de atuação, a companhia estatal tornou-se sócia do Intelsat (Consórcio Internacional de Comunicações por Satélite), formado, na época, por 11 países. Essa associação visava à formação de um único sistema mundial de comunicações por satélite. Nas duas primeiras décadas da empresa, coincidentes com o regime militar, as políticas implementadas pela Embratel foram altamente insuladas, do ponto de vista de decisão burocrática, com forte ênfase técnica.
Não havia debate aberto sobre as decisões da empresa nos meios de comunicação. Esse era um momento fundador, fase de criação, implantação e entrada em operação do sistema nacional e internacional de telecomunicações; quem viabilizava essa dinâmica atuação eram os militares, juntamente com o corpo de técnicos, em um contexto político autoritário. As discussões ocorridas tinham basicamente um caráter técnico: planos, prioridades e a sua operacionalidade ${ }^{6}$. Desfazia-se assim o debate político e ideológico sobre quem deveria conduzir a política de telecomunicações: Estado ou mercado.

Organograma 1 - Quadro institucional das telecomunicações

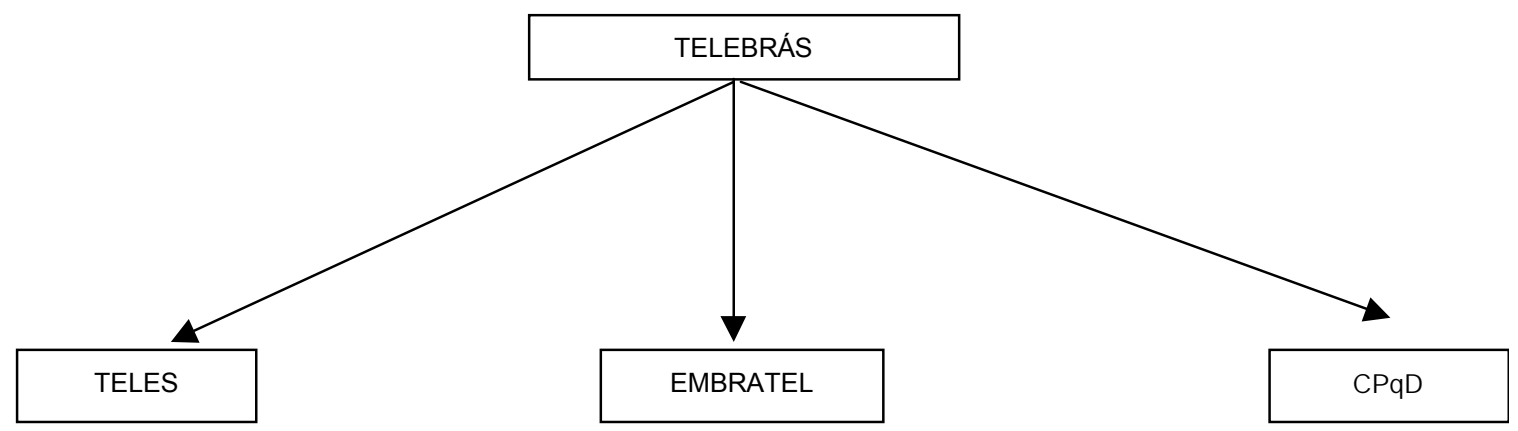

Na gestão de Costa e Silva, em 1967, foi transferido para a União o poder de exploração dos serviços telefônicos. A partir desse ano a Embratel, até então subordinada diretamente à Presidência da República, passou a vincular-se ao Ministério das Comunicações (EMBRATEL, 1980). O Conselho Nacional de Telecomunicações (CONTEL) e o Departamento de Correios e Telégrafos (DCT) ficaram também subordinados ao novo Ministério.

A atuação inaugural da Embratel no campo da telefonia consistiu na operação do tronco BrasíliaRio de Janeiro até então explorado pela Novacap ${ }^{7}$. Em 1968 a Embratel iniciou a implantação do sistema de troncos telefônicos da Amazônia. No ano seguinte passou a operar com exclusividade os troncos internacionais. Nesse mesmo período foi inaugurada a Estação Terrena de Tanguá, em Itaboraí, no interior do estado do Rio de Janeiro,

\footnotetext{
6 Muitas dessas discussões eram centradas no Centro de Pesquisa e Desenvolvimento da Telebrás (CPqD).

7 Empresa constituída no governo Juscelino Kubitschek, no final dos anos 60 , destinada à construção da nova capital do país.
}

visando a se integrar no Intelsat. Com a nova Estação, a Embratel começou a operar via satélite, os serviços internacionais de telefonia, de telex e telegrafia e de canal para TV. Foi também inaugurado em 1969 o Tronco Sul, ligando as cidades de Curitiba e Porto Alegre. Nesse momento começava uma revolução nas telecomunicações brasileiras. Os telefones e a televisão chegavam às regiões mais afastadas do país, e a conexão telefônica via satélite possibilitava uma operação mais ágil entre as regiões brasileiras e uma comunicação cada vez mais abrangente do Brasil com o mundo. As tevês puderam transmitir a chegada do homem à lua em 1969 e o Campeonato Mundial de Futebol em 1970.

No governo de Emílio Garrastazu Médici inauguraram-se os novos troncos Brasília-Rio de Janeiro, Rio de Janeiro-Florianópolis e Belo Horizonte-Salvador. Nesse período foi instalado o sistema DDD (Discagem Direta à Distância), ligando entre si várias cidades brasileiras. Em 1971 a Embratel passou a explorar o Serviço Móvel Marítimo, que possibilitou a comunicação por voz e texto a partir do mar, ou de um rio ou lago para a terra, usando a Rede Nacional de Estações Costeiras (RENEC). 
Logo a Embratel cobriu todo o território nacional com o sistema de troncos, através da rede Porto Velho-Manaus, interligando, assim, todas a capitais brasileiras (EMBRATEL, 1973). Num curto espaço de tempo, os altos investimentos e a atuação intensa de um corpo técnico iam colocando em prática as metas da política de comunicações traçadas desde o projeto aprovado em 1962: uma política que supunha o setor de telecomunicações como monopólio governamental, a centralização das operações e a unificação do sistema. O Brasil acompanhava o salto tecnológico das telecomunicações no mundo e realizava o feito de unir um enorme território através da rede de telefones, TV e transmissão de dados.

A criação de um sistema nacional de telecomunicações encerrou finalmente as atividades das concessionárias estrangeiras Western Cable \& Wireless (telex), Radiobrás (RCA), Italcable e Radional (ITT).

Um outro salto tecnológico promovido pela política de telecomunicações foi a inauguração pela Embratel, em 1973, do cabo submarino Bracan, ligando o Brasil à Europa, via Ilhas Canárias.

O processo de expansão dos serviços de telecomunicações teve continuidade durante os governos militares que se seguiram (Ernesto Geisel e João Baptista Figueiredo). Apesar da crise mundial de 1973 e 1979 (choque do petróleo), os dois últimos governos militares deram continuidade ao projeto desenvolvimentista, expandindo os serviços com a mais alta tecnologia ${ }^{8}$. Nesses governos o serviço DDI (Discagem Direta Internacional) foi ampliado para 75 países e inauguraram-se as estações Tanguá II e II, garantindo o aumento do grau de confiabilidade das comunicações via satélite. Nessas estações operavam o sistema Intelsat, ligando o Brasil a vários países.

Visando à operação e exploração comercial das comunicações marítimas, a Embratel filiou-se, em 1978, a um novo consórcio internacional, o Inmarsat (International Maritime Satelite Organization), quando foi também ampliada a Rede Nacional de Estações Costeiras, medida fundamental para um país com uma costa marítima tão extensa.

\footnotetext{
8 Contudo essa diretriz política aguçou a crise financeira do Estado e a ampliação dos índices inflacionários na década seguinte (ALMEIDA, 1996, p. 216).
}

Apesar de todo o avanço tecnológico nas comunicações, o Brasil continuava com um enorme déficit de linhas telefônicas. Embora tenha sido aumentado de 1,4 telefone por 100 habitantes em 1960 para 5,4 no final da década de 70, a densidade telefônica ainda era baixa considerando a demanda interna por linhas e comparando-se com a Argentina (10 telefones por 100 hab.), com Portugal (30 por 100), França (43 por 100) e Estados Unidos (75 por 100) (EMBRATEL, s/d).

$\mathrm{O}$ avanço da política de telecomunicações teve continuidade nos anos 80 , a despeito da séria crise econômica que atingiu o país no período. Em 1980 foi inaugurado o cabo submarino analógico Brus ligando o Brasil aos EUA. Logo depois se instalou o cabo Atlantis, ligando a cidade de Recife a Dakar e Lisboa, estabelecendo a conexão Brasil-ÁfricaEuropa (EMBRATEL, 1983). Nesse esforço de integração e internacionalização da política de telecomunicações inseriu-se o Interdata, que visava a estimular a atuação brasileira no comércio internacional por meio da tecnologia digital na transmissão de sinais, voz e dados (Revista Via Embratel, out.1988) $)^{9}$.

No último ano do regime militar implantou-se a Rede Nacional de Comunicação de Dados por Comutação de Pacotes (Renpac) (1984), visando à melhoria da comunicação entre empresas $\mathrm{e}$ instituições em todo o território nacional. Nesse ano, ainda foram inaugurados o centro de operações do sistema de satélite Brasilsat I e a antena Tanguá IV ${ }^{10}$.

O crescimento econômico do país entre 1968 e 1980 permitiu à Embratel investir crescentemente na implantação de um sistema integrado e centralizado de telecomunicações, interligando o país através de seus serviços. Esse projeto tecnológico possibilitou não apenas o alcance das metas originalmente formuladas para o setor - como a padronização tecnológica e a interação de serviços - mas também serviu de base para a propaganda dos governos militares de suas políticas relativamente bem sucedidas. No momento em que se

\footnotetext{
9 A Portaria n. 105, de 21 de janeiro de 1978, delegou à Embratel a atribuição de explorar os serviços de comunicação de dados no Brasil. Nesse mesmo ano ocorreu o início das comunicações marítimas via Inmarsa.

10 A nova antena foi destinada ao tráfego do serviço de ligações marítimas na região do oceano Atlântico.
} 
esgotava o domínio militar, as Forças Armadas mostravam os feitos de sucesso para buscar legitimação no poder. Alegavam que haviam atingido os objetivos iniciais. Todo o território brasileiro estava conectado internamente do ponto de vista das telecomunicações e o Brasil podia ligar-se ao restante do mundo mediante as tecnologias mais avançadas.

Contudo, a década de 80 foi paradigmática não apenas para os rumos do setor de telecomunicações, mas para o encaminhamento da economia brasileira. Naquele momento a crise econômica aguçou-se, com um quadro de recessão, de crise fiscal e de endividamentos interno e externo. As causas da crise do Estado brasileiro, destacadas por Bresser Pereira, podem ser encontradas na sua incapacidade fiscal, que se expressa pelo déficit público, mas também pelo endividamento externo. Esses fatores impossibilitaram naquele momento o Estado de promover suas atividades essenciais (Bresser Pereira apud DINIZ, 1998, p. 11).

O economista José Luis Fiori argumenta que a crise dos anos 80 não foi apenas de cunho fiscal. Na realidade, nesse momento se desencadeou um questionamento mais amplo do próprio modelo econômico e de industrialização que até então tinha sido promovido, tendo, portanto, também um caráter político. Uma das principais conseqüências da crise do Estado foi a crescente "degradação da infra-estrutura econômica e uma acelerada deterioração dos serviços públicos" (FIORI, 1991, p. 1112). Esse processo teve como conseqüência o rompimento da coalizão política que sustentou o modelo. A partir desse momento, reconhece Fiori, houve "uma dissociação da nossa burguesia com um modelo que ela considerava cada vez mais próximo de um inaceitável "capitalismo e de Estado"' (idem, p. 12).

Entre os fatores externos que contribuíram para uma possível redefinição do modelo desenvolvimentista, podemos destacar o Consenso de Washington, como um dos principais núcleos do ideário favorável ao fim da atuação direta do Estado nos segmentos econômicos, à liberalização, à desregulamentação e à privatização (DINIZ, 1998, p. 6).

Com a mudança de regime político, o sistema de telecomunicações entrou numa área de grande incerteza. Os militares foram progressivamente afastados das empresas estatais ligadas ao setor. A gestão do Sistema Nacional de Telecomunicações foi politizada, uma vez que o Ministro das Comuni- cações deixou de ser um militar, como no regime anterior, e passou às mãos de Antônio Carlos Magalhães, político fundamental no arranjo político que levou José Sarney à Presidência da República em 1985.

Para fazer frente ao quadro de crise econômica a referida década foi marcada pela promoção de vários planos de estabilização que tiveram um resultado pífio, além de um profundo conflito de interesses - não apenas entre os segmentos políticos e partidários que estavam tradicionalmente em confronto, mas no interior da própria elite dirigente que estava à frente das decisões.

Embora restringidos financeiramente pela crise econômica, os investimentos para a expansão das telecomunicações continuaram sob a Nova República, mas permanecia no ar uma dúvida quanto ao verdadeiro objetivo da expansão do sistema: suspeitava-se que os investimentos estavam preparando o sistema para a privatização advinda da quebra do monopólio estatal na área.

No governo de José Sarney continuou a expansão das telecomunicações, com o lançamento do satélite Brasilsat, que possibilitou a cobertura total do território brasileiro no campo da telefonia, TV, telex e comunicação de dados (O DESAFIO DE 20 ANOS, 1985). Assinou-se a regulamentação do Serviço Especial de TV por Assinatura (TVA) comandado pelo governo. Esse serviço - que permitiu a transmissão de informações, dados, textos e programa de som e imagem - teria a Embratel como locatária (Correio Brasiliense, 24.fev.1988).

Com a nova Constituição de 1988 manteve-se o modelo monopolista estatal nas telecomunicações ${ }^{11}$, operado diretamente pela União. É interessante notar que o cunho desenvolvimentista do modelo econômico permaneceu na nova Carta Magna. Este padrão expressou-se na confirmação do monopólio estatal em outros setores estratégicos como petróleo, energia, portos etc. No campo da ampliação tecnológica promovida pela Embratel, passaram a funcionar também nesse período

\footnotetext{
11 No Art. 21, XI, da Constituição de 1988, atribuiu-se à União a competência de "explorar diretamente ou mediante concessão às empresas sob o controle acionário estatal, os serviços de telefonia, telegráficos, de transmissão de dados e demais serviços públicos de telecomunicações, assegurada a prestação de serviços de informações por entidades de direito privado através da rede pública explorada pela União".
} 
vários serviços: o Brasil Direto ${ }^{12}$ e o Home Country Direct, novas tecnologias que permitiram aumentar a confiabilidade das ligações internacionais. Em 1989 o DDI foi ampliado para mais 14 países, entre eles a União Soviética, alcançando naquele momento 154 nações (EMBRATEL, 1989).

No início dos anos 90 os governos Fernando Collor e Itamar Franco continuaram a investir na expansão das telecomunicações, embora constrangidos pela crise financeira e fiscal do Estado, que já perdurava uma década. O governo Itamar Franco particularmente assumiu claramente o projeto de modificar o modelo de intervenção estatal com a promoção de políticas de privatização e de liberalização comercial (ALMEIDA, 1996, p. 217).

No cenário das estratégias formuladas e efetivadas pela Embratel, ampliou-se a estação de satélites de Morungaba, em São Paulo, a Renpac (Rede Nacional de Pacotes) e a rede de dados Transdata $^{13}$. Nesse momento a Embratel já oferecia 38 serviços de voz, textos, dados, telemáticos, som e imagem e comunicações móveis. Entrou em operação nessa época o tronco ótico Rio de JaneiroSão Paulo. O sistema de fibra ótica expressou um novo avanço da tecnologia de telecomunicações, pois possibilitou o aumento na velocidade de transmissão de dados e diminuiu o seu custo de operação. Outra inovação foi o cabo submarino Americas, operado por fibras óticas e pelo sistema digital, ligando o Brasil ao restante do continente americano. Ao mesmo tempo foi inaugurada a segunda geração da rede Renpac. Ao final do governo de Itamar Franco (1994) cerca de $73 \%$ da rede de telefonia já operava no sistema digital.

Apesar da garantia do monopólio estatal das telecomunicações na Constituição de 1988, permanecia a incerteza com relação às intenções dos

12 O serviço possibilitou realizar ligações de qualquer telefone estrangeiro para o Brasil com um ambiente falado em português.

13 Morungaba I foi uma antena construída com a finalidade de transmissão e recepção da telefonia e TV internacionais. Morungaba II foi dedicada à transmissão da TV nacional. Morungaba III era referente à comunicação de dados em nível internacional. Morungaba IV foi destinada à restauração de tráfego nos cabos submarinos Américas e Unisur. O Transdata possibilitou a comunicação de dados em âmbito nacional. governos em privatizar as empresas do sistema e quebrar o monopólio do governo no setor. Essa incerteza teve fim no governo de Fernando Henrique Cardoso, responsável pela grande virada nas telecomunicações brasileiras, com a quebra do monopólio e a privatização das empresas ligadas ao setor. Esse processo não parece contudo ter paralisado o setor, que continuou a expandir-se e a contar com largos investimentos governamentais, agora sabidamente visando a preparar o campo para as privatizações e atrair investidores para o processo.

Em 1994 foi lançado o Teleporto do Rio de Janeiro através de um vídeo-conferência entre o Rio de Janeiro e a cidade de Nova York. O teleporto visava a tornar o Rio de Janeiro uma cidade aberta ao comércio internacional. Nesse ano lançou-se o satélite doméstico Brasilsat B1, o sistema de troncos digitais ampliou-se e entraram em operação os cabos submarinos Unisur (Cone Sul) e Columbus II (Europa).

Em 1995 foi lançado o Brasilsat B2, iniciada a construção da rota óptica Rio de Janeiro-Fortaleza e inaugurado o tronco óptico Rio de Janeiro-Belo Horizonte. Nesse período foi anunciada a construção do cabo submarino ótico Cabral Atlantis II e ocorreu a primeira transmissão de TV do exterior via Brasilsat, viabilizando a entrada do país na era da TV a cabo.

Após três décadas da sua constituição, a Embratel em 1995 cobria mais de 4600 localidades com telefonia via DDD e alcançava 203 países. Naquele ano a empresa contava com 12 mil funcionários e teve um faturamento de $\mathrm{R} \$ 1,27$ bilhão. Cerca de $60 \%$ de sua receita operacional advinha dos serviços de voz, $29 \%$ dos serviços telemáticos de dados e $7 \%$ de textos. O sistema de fibra ótica tinha uma rede de 32,8 mil km (Telebrasil, set.out.1995) $)^{14}$.

Em 1996 a estatal teve um lucro líquido de R\$ 406 milhões e completou a interligação por fibra ótica entre as cidades de Fortaleza e Florianópolis. Buscando ajustar-se às novas exigências políticas que sinalizavam a projeção de uma estratégia opera-

14 Nesse ano a empresa ampliou o tráfego de telefonia pública em $13 \%$, da telefonia internacional em $24 \%$, da Renpac em 111\% e do STM 400 em 84\%. Este último serviço é especializado em mensagens de dados em níveis nacional e internacional. 
cional em um mercado que estava prestes a tornarse competitivo e privatizado, a empresa criou a Diretoria de Serviços de Telecomunicações, destinada a atender especificamente os seus clientes (EMBRATEL, 1996; Gazeta Mercantil, 15.mar.1997; 16.mar.1997).

No campo dos investimentos tecnológicos a Embratel expandiu suas redes de dados e inaugurou o serviço de comunicação de dados utilizando a tecnologia Frame Relay, que possibilitou o barateamento desse serviço de telefonia. Ainda em 1996 a empresa alcançou $81 \%$ de digitalização de sua rede telefônica de longa distância. No âmbito da comunicação de dados sua capacidade de transmissão foi ampliada em 16\%. Passou a participar do projeto Sintonia que reunia as empresas do setor de telecomunicações dos países do Mercosul, visando a expansão e melhoria qualitativa da comunicação nessa área (ibidem; ibidem).

Às vésperas da sua privatização a Embratel lançou-se a um intenso programa de capacitação e qualificação de seus funcionários ao mesmo tempo que continuava a expandir-se ${ }^{15}$. Nesse período a empresa promoveu a expansão e melhoria da qualidade de operação da Rede Nacional de Comunicação de Dados e Telemáticos, da Multirede Digital e da internet.

Ao longo dos seus primeiros 30 anos a Embratel acompanhou o salto tecnológico que se configurou na evolução das comunicações por meio da telefonia para comunicação de dados, voz e textos e das redes corporativas. Nos anos 90 incorporou as mais avançadas tecnologias de telecomunicações por satélites, a digitalização das redes e os avanços na área de transmissão de dados.

Com essa estrutura o Sistema Telebrás passou a ter uma das maiores plantas de telecomunicações do mundo (19 milhões de terminais). O mercado de telecomunicações tornou-se significativo, sendo $30 \%$ maior que os mercados do Chile, Argentina e Peru somados. Contudo, apesar do seu avanço

$\overline{15}$ Estava concluída a interligação entre Belo HorizonteBrasília, Florianópolis-Porto Alagre, São Paulo-CuritibaFlorianópolis, Rio de Janeiro-São Paulo-Belo Horizonte. Ao longo de 1997 o programa de fibras óticas de longa distância prosseguiu com a implantação das rotas SalvadorFortaleza, Brasília-Goiânia, Porto Alegre-Uruguaiana (Brasil)-Pasos de los Libres (Argentina), Porto AlegreAlegrete-Santana do Livramento (Brasil)-Rivera (Uruguai), Goiânia-Palmas-Santa Inês e Rio de Janeiro-Natal. e de todo o investimento, o sistema de telecomunicações no início dos anos 90 não atendia à demanda real do país. Ainda havia um déficit de serviços e uma baixa qualidade operacional, devida especialmente à baixa qualidade de gestão das estatais a partir da politização do setor na Nova República.

Ao completar 33 anos de atividades, como empresa estatal e monopolista, a Embratel foi privatizada em leilão na Bolsa de Valores do Rio de Janeiro, no dia 29 de julho de 1998, adquirida pela empresa norte-americana MCI World Com. Sua venda deu-se após um amplo programa de reestrutura-ção, iniciado em 1995, com a finalidade de torná-la uma companhia habilitada a atuar em um con-texto institucional privatista e competitivo. Alega-va-se que, passando a atuar como uma empresa privada e competitiva, num sistema de telecomuni-cações privado, o déficit de serviços em telecomu-nicações seria atendido.

\section{O PROCESSO DE PRIVATIZAÇÃO DA EM- BRATEL (1995-1998)}

Privatizar a Embratel foi parte de um processo mais amplo que envolveu a quebra do monopólio estatal no setor de telecomunicações, a venda das empresas que operavam no setor (as "Teles" estaduais, a Embratel e a Telebrás) e que foi conduzido pelo Ministro das Comunicações Sérgio Motta. A Embratel levou quatro anos para tornar-se uma empresa privada e inserir-se em uma estrutura competitiva.

Desde o início do governo Fernando Henrique Cardoso buscou-se na privatização uma solução para a incapacidade do Estado de continuar a investir para expandir o setor de telecomunicações. A primeira etapa do processo de privatização da Embratel teve lugar no Congresso Nacional, com a votação da Emenda Constitucional n. 8, que quebrou o monopólio estatal das telecomunicações (em agosto de 1995). No ano seguinte o Executivo decidiu abrir à competição o serviço de telefonia móvel. Em 1997 o governo enviou ao Congresso uma ampla proposta de legislação para o setor (Lei Geral de Telecomunicações), para substituir o Código Brasileiro de Telecomunicações. Finalmente, em 1998 a Embratel, juntamente com as demais companhias que compunham o Sistema Telebrás, foram efetivamente privatizadas.

É interessante notar, contudo, que a empresa começou a tornar-se alvo das propostas privatistas desde a segunda metade da década de 80 , com a 
mudança de regime político no país e as primeiras cogitações de terceirizar alguns dos seus serviços. Os militares estavam profundamente identificados com o monopólio estatal do setor de telecomunicações e teria sido muito difícil flexibilizar esse monopólio se não tivesse havido a mudança de regime e o afastamento dos militares do poder (Leia e fique sabendo, 1993) ${ }^{16}$.

Durante o processo constituinte (1987-1988), ocorreu um intenso debate no Congresso Nacional, refletido também em vários setores da sociedade, acerca da continuidade do sistema estatal e monopolista de telecomunicações. A posição que prevaleceu na Constituição de 1988 foi a que favorecia a manutenção do monopólio estatal.

No entanto, a partir da segunda metade da década de 90 a proposta privatista voltou à tona $\mathrm{e}$ ganhou espaço, influenciada pelos acontecimentos internacionais - o fim da Guerra Fria, o processo de globalização, o Consenso de Washington e, nas telecomunicações, a privatização da companhia telefônica inglesa British Telecom - e também por motivos internos, como as políticas de ajuste e de reformas em curso na Nova República.

O processo de reformas proposto pelo governo de Fernando Henrique Cardoso, do qual a revisão constitucional em 1995 fazia parte, envolvia as seguintes áreas: gás canalizado, definição de empresa nacional, navegação de cabotagem e a quebra do monopólio estatal dos setores do petróleo e das telecomunicações (O Globo, 07.jul.1995).

Na realidade o projeto de privatização das telecomunicações esteve inserido em um programa mais amplo que alterava o padrão do domínio do Estado na economia, que incluía a privatização, a liberalização do comércio externo e do sistema previdenciário.

Esse modelo de reformas estruturais na economia brasileira foi estimulado pelas agências multilaterais (FMI e Banco Mundial, GATT-OMC), cujo

\footnotetext{
16 A empresa Victori - uma sociedade do Bradesco com a Rede Globo e a empresa italiana Victori Internacional solicitou ao Ministério das Comunicações licença para usar o Brasilsat da Embratel. A proposta considerava que aqueles que quisessem vender informações deveriam usar os serviços da Victori. Houve uma reação unânime no interior da empresa e fora dela contra a referida proposta, impedindo, assim, sua concretização, que era considerada pelos sindicatos do setor e pela própria direção da Embratel como contrária aos interesses nacionais.
}

receituário nos anos 90 incluía o fim de monopólios estatais e desregulamentação de setores até então reservados às empresas privadas locais. $\mathrm{O}$ setor financeiro e amplos segmentos da imprensa também posicionavam-se como favoráveis à implantação da reforma.

As maiores resistências no Congresso Nacional concentraram-se na quebra do monopólio estatal do petróleo e das telecomunicações. O projeto de reforma deste último setor sofreu a ação de grupos de interesses que atuavam no Congresso, no interior dos partidos políticos, e que representavam empresas nacionais e internacionais e sindicatos de trabalhadores dos setores de telecomunicações.

A Comissão Especial de Telecomunicações, constituída no Congresso com a finalidade de debater a questão da quebra do monopólio do setor, era formada por 30 parlamentares. A representatividade dos partidos políticos na comissão era proporcional ao peso de cada agremiação partidária no Congresso. Em maio de 1995 a Comissão aprovou a proposta de flexibilização do monopólio das telecomunicações (Jornal do Brasil, 07.maio.1995).

Com a aprovação da Emenda Constitucional n. 8 em agosto de 1995, que tratou da flexibilização do setor, os serviços de telecomunicações, até então operados por companhias estatais, foram transferidos para o setor privado.

Dando continuidade à reestruturação das telecomunicações, em 1996 o governo enviou ao Congresso o Projeto de Lei Mínima das Comunicações visando a regulamentação da telefonia celular. Em julho desse ano a Lei Mínima foi aprovada, passando a regular a entrada da iniciativa privada no segmento da telefonia móvel e na comunicação de satélites (Jornal do Brasil, 19.jul.1996; 20.jul.1996).

O governo esforçou-se por criar uma nova legislação que substituísse o Código Brasileiro de Telecomunicações de 1963. Novamente o debate veio à tona com a participação de grupos contrários e favoráveis à reforma do setor e, em especial, a privatização da Embratel. Os partidários da privatização alegavam que as empresas estatais tinham capacidade de fazer investimentos para universalizar os serviços de telecomunicações. Os que se opunham à reestruturação consideravam que o Estado ainda deveria ser o agente central da modernização do setor. 
Em junho de 1997 o Congresso Nacional aprovou a Lei Geral de Telecomunicações (Lei n. 9 472, de 16 de julho de 1997) que representou uma mudança programática e estrutural no setor. O novo ordenamento legal substituiu o modelo monopolista estatal, pondo fim ao papel de poder concedente da União. Terminava assim a era da atuação direta do Estado na operação dos serviços de telecomunicações (Jornal do Brasil, 19.jun.1997; O Globo, 19.jun.1997). A nova lei autorizou o governo a privatizar o Sistema Telebrás e garantiu a criação da Agência Nacional de Telecomunicações (ANATEL), com a finalidade central de implementar a política de telecomunicações por meio da regulação e fiscalização da operação das companhias do setor, visando ao cumprimento da meta da ampliação e universalização dos serviços. A agência ganhou o status de uma autarquia, dotada de autonomia financeira e administrativa. Os dirigentes têm um mandato fixo e estabilidade.

A cientista política Maria Hermínia Tavares de Almeida destaca que todo o processo decisório de reestruturação do Estado promovido pelo governo de Fernando Henrique Cardoso, e em especial da mudança das telecomunicações, esteve ancorado em uma natureza nitidamente pragmática, opondo-se, conseqüentemente, tanto ao ordenamento estritamente neoliberal como ao tradicional ideário econômico desenvolvimentista (ALMEIDA, 2001, p. 53-54).

Por meio da nova legislação afeta ao setor de telecomunicações o segmento da telefonia fixa de longa distância ficou dividido em três regiões:

1) região I - constituída pelos estados do Amazonas, Pará, Roraima, Amapá, Maranhão, Piauí, Ceará, Rio Grande do Norte, Paraíba, Pernambuco, Sergipe, Alagoas, Bahia, Rio de Janeiro, Espírito Santo e Minas Gerais;

2) região II - formada pelos estados do Rio Grande do Sul, Santa Catarina, Paraná, Mato Grosso do Sul, Mato Grosso, Goiás, Tocantins, Rondônia e Acre, além do Distrito Federal;

3) região III - cobrindo exclusivamente o estado de São Paulo.

O segmento da telefonia fixa (local e longa distância intrarregional) é formado por 34 empresas concessionárias, na sua maioria antigas empresas estatais de nível estadual ("Teles"). Nesse campo atuam operam, ainda, 3 empresas "espelhos" de âmbito regional. A expansão do setor de telefonia fixa, especialmente na segunda metade da década, não teve precedentes na história brasileira: em 1990 o Brasil contava com 10,3 milhões de linhas telefônicas fixas. Cinco anos depois já havia 14,5 milhões. Em junho de 2001 esse número chegou a 43,3 milhões. No campo da telefonia celular/móvel o país passou de 1,4 milhão de aparelhos em 1995 para 25 milhões em 2001 (Jornal do Brasil, 26.ago.2001).

A Embratel S/A opera na região IV, que faz a cobertura de todo o território nacional e atua no campo da telefonia internacional. A empresa concorre com a companhia "espelho" Intelig, mas detém ainda a maior parte do segmento de longa distância (44\%) (Gazeta Mercantil, 23.ago.2001), enquanto a Intelig detém apenas $3 \%$ do mercado, ficando o restante para as concessionárias que fazem ligações interurbanas regionais (Telefônica, Telemar e Brasil Telecom). Desde meados de 2001 tem havido uma acirrada concorrência entre essas duas empresas, através do barateamento das tarifas dos serviços telefônicos para o exterior. Existem ainda cerca de 22 empresas "espelhinhos" concorrendo no âmbito local, longa distância nacional e longa distância internacional

O setor de telefonia celular-móvel foi segmentado em 10 grandes áreas, com 11 concessionárias atuando na Banda A e 9 empresas atuando na Banda B e competindo entre si. Os serviços de telefonia fixa e celular são os mais populares no campo das telecomunicações e têm passado por um intenso processo de competição que se expressa no preço das tarifas telefônicas.

A Embratel, já como empresa privada, continuou a fazer investimentos no sentido de atuar tecnologicamente e expandir sua capacidade de operação. No mesmo ano da sua privatização, a empresa implantou os seguintes novos serviços:

1) EmVia - serviço de suporte ao comércio eletrônico, que atua na área de mensagens e de interação de empresas;

2) ATM - serviço com aplicação na longa distância visando à interconectividade de redes locais geograficamente dispersas. Videoconferência de grandes arquivos, distribuição de vídeos, CAD-CAM, telemedicina, teleducação e entretenimento;

3) DDD plus - serviço que permite ao cliente descontos de $20 \%$ no DDD e proporciona também ganhos em produtividade e qualidade; 
4) 0800 inteligente - serviço de ligação gratuita que apresentou uma série de novas facilidades como acesso do usuário aos diversos serviços, direcionando a ligação à central de atendimento mais próxima.

Ainda em 1998 foi lançado satélite Brasilsat B3 para desafogar o Brasilsat B2 ${ }^{17}$.

Visando a inserir-se em um mercado competitivo a partir de 1999, a Embratel desenvolveu o Plano dos Cem Dias, um programa de redução dos custos, e a fim de atender as metas da ANATEL no sentido de ampliar a qualidade e buscar a universalização dos serviços. Esse mesmo ano foi marcado pela chegada da Internet Via Embratel, a entrada em atividade do cabo óptico Atlantis 2, ligando a América do Sul (Fortaleza e Las Toninas, na Argentina) à África (Dakar, no Senegal, e Cabo Verde) e à Europa (Sesimbra, em Portugal, e Ilhas Canárias, na Espanha) ${ }^{18}$.

Atualmente $61 \%$ da receita da Embratel provém de serviços de longa distância nacional, 24\% da comunicação de dados e $11 \%$ das ligações internacionais. Desde a crise brasileira de 1998-99, que corresponde ao momento da privatização da Embratel, a empresa vem encontrando dificuldades e desacelerando seus investimentos. Seus problemas de receita advêm principalmente do impacto que sofreu com a desvalorização crescente do Real desde o início de 1999 (que aumentam a dívida contraída no exterior), dos impostos e dos usuários inadimplentes (mais de $500 \mathrm{mil}$ ), que já respondem por uma proporção equivalente a $8,8 \%$ da receita líquida da empresa (Gazeta Mercantil, 25.out.2001).

Maria Hermínia Tavares de Almeida destaca que um dos fatores que permitem considerar que o processo de reforma do Estado brasileiro e, em especial, o das telecomunicações, foi lento e gradual é a falta de consenso entre a própria elite dirigente acerca dos rumos que Estado deveria ter na condução da economia nacional. Ainda nos 80 anos

\footnotetext{
17 O referido satélite passou a ser utilizado nas transmissões de televisão aberta por assinatura, serviços de telefonia e comunicação de dados.

18 A Embratel faz parte de consórcio internacional com outras nove empresas de telecomunicações. O referido cabo submarino está interligado aos sistemas Américas 1, Columbus 2, Unisur, Sea-Mea-We 3, Pencan 6 (Espanha) e Tagide 2 (França).
}

setores importantes como os militares e a burocracia estatal tinham uma visão claramente intervencionista (ALMEIDA, 1996, p. 221). Um outro fator foi o segmento do poder que ficou à frente do país a partir do término do período autoritário ser formado pela centro-esquerda e pelos dissidentes do regime com uma clara visão desenvolvimentista. Esse argumento confirma-se pelas próprias decisões da Constituinte de 1988, que preservaram ou ampliaram a centralidade do Estado nos universos econômico e social. Em 1984 surgiram as primeiras vozes favoráveis à privatização de alguns dos serviços operados pela Embratel, contudo o setor e a empresa somente foram efetivamente privatizados no final dos anos 90, ou seja, 14 anos depois dos primeiros clamores privatistas.

É interessante notar que a reforma promovida no setor não obedeceu stricto sensu à lógica neoliberal. O projeto promovido pelo governos de Fernando Henrique Cardoso reconhecia que o Estado não tinha capacidade financeira para expandir o setor, mas, uma vez promovido o que era considerado essencial - privatização de empresas estatais, liberalização da economia visando a reduzir o déficit do Estado, entre outras decisões - deveria, ainda sim, ter o Estado um papel central na regulação das ações das novas empresas privadas (idem, p. 222). Em seus aspectos normativos o campo das telecomunicações ilustra esse cenário, ou seja, o setor encontra-se hoje nas mãos do capital privado, em grande parte internacional, com o Estado regulando por meio da Agência Nacional de Telecomunicações as metas operacionais e os investimentos do setor (ALMEIDA, 2001, p. $54)^{19}$. Uma questão central e que deve estar na pauta de discussão refere-se à capacidade do governo fazer frente ao poderio econômico dos grupos privados e das possíveis ingerências clientelistas no interior da própria agência reguladora.

O cientista político Marcos André Melo destaca que o funcionamento de tais agências tem como crítica central o "seu déficit democrático" 20 , uma

\footnotetext{
19 A autora destaca que o modelo brasileiro elegeu "lo que los norte-americanos han llamado statutory regulation, o sea, el de la agencia reguladora independiente basada em um mandato legal" (ALMEIDA, 2001, p. 54).

20 "Nesse sentido, sua autonomia e independência representam uma ameaça ao interesse público na medida em que agentes não-eleitos tomam decisões relevantes para sociedade" (MELO, 2000, p. 9).
} 
vez que tais órgãos são ocupados por atores que estão de certo modo alheios aos contornos políticos da sociedade. Se por um lado os critérios puramente técnicos foram constituídos visando a evitar ingerências políticas nocivas ao encaminhamento estratégico das telecomunicações, por outro lado o seu enquadramento puramente técnico coloca um outro aspecto fundamental, ou seja, a ausência de controle das decisões e ações dos atores no interior da Agência por parte da sociedade mais ampla.

\section{CONCLUSÃO}

Partimos do princípio de que a criação da Embratel e sua privatização corresponderam ao cenário sócio-político-econômico mais amplo da década de 60. Esse processo sofreu a influência tanto de fatores endógenos - que remetem a um papel central da elite dirigente nacional nas decisões do setor -, quanto obedeceram às diretrizes ditadas pela economia e pelos órgãos financeiros internacionais, sobretudo no que diz respeito ao recente processo de privatização ao longo da década de 90 .

Se por um lado a empresa no cenário estatista promoveu um verdadeiro salto tecnológico no campo das telecomunicações, constituindo um sistema interligado e unificado para todo o país, por outro a falta de acesso à telefonia fixa revelava um impasse no referido contexto do avanço tecnológico do setor.

O cenário à frente da Embratel aparece cheio de incertezas. De um lado, a conjuntura externa não estimula perspectivas de melhores dias, enquanto no âmbito interno a empresa defrontase com problemas de receita. Além disso uma nova mudança no sistema de telecomunicações brasileiro está por vir. A Lei Geral de Telecomunicações de 1997 estabeleceu que a partir de 2003 o setor será desregulamentado e a livre concorrência será estabelecida entre as empresas, hoje operando em fatias segmentadas de setores e territórios nacionais. Terá fim a divisão por áreas para as operadoras de telefonia fixa, que poderão então atuar em qualquer setor e região. Como responderá a nova Embratel, uma empresa de capital estrangeiro, a um mercado competitivo no qual será desafiador manter a fatia de quase $50 \%$ das operações com o exterior na área de telecomunicações? Estará preparada para entrar no mercado de telefonia local a partir deste ano, reunindo um pacote de ofertas de serviços a empresas e usuários que envolva serviços locais, telefonia internacional, serviços de dados e de internet, tal como faz a MCI World Com. nos Estados Unidos?

Em boa parte da trajetória da Embratel foi ao Estado brasileiro que a empresa deveu a grande capacidade de crescer e de colocar o país em conexão com o mundo a partir das tecnologias mais avançadas. A Embratel estatal colocou o Brasil no século XXI em matéria das telecomunicações, mas não atendeu aos milhões de brasileiros que ansiavam por uma linha telefônica. Agora essa capacidade de crescer cabe à nova Embratel, uma empresa privada estrangeira, cujo poder de decisão maior quanto aos investimentos reside fora do país, na matriz norte-americana. O futuro dirá qual dos modelos melhor beneficiou o usuário e expandiu as telecomunicações no país.

Atualmente a Embratel insere-se em um contexto econômico de competição regulada; contudo, um processo de liberalização mais enfático aproxima-se, tanto no campo da ampliação dos serviços como no valor das tarifas telefônicas.

No cenário pós-privatização, embora tenha cumprido as metas de universalização para o ano de 2003 e, por isso, tenha sido autorizada a operar em outros segmentos que não apenas o de telefonia de longa distância, a empresa sofrerá uma competição no campo das ligações internacionais, que é um segmento importante de geração de receitas (Folha de S. Paulo, 26.abr.2002).

As responsabilidades acerca da ampliação dos serviços de longa distância de telecomunicações e da sua qualidade não estão, agora, apenas nas mãos da Embratel, mas também são atribuições de outras empresas que atuam na referida área. Mais do que nunca a regulação por parte do governo federal, por meio da ANATEL, torna-se crucial, nas operações de telefonia e telecomunicações em geral. Essa instância deve estar preparada para evitar uma competição perversa que não interessa à sociedade, assim como deve estar atenta aos riscos de uma possível monopolização do setor, que igualmente não é benéfica para a sociedade. Em princípio tais riscos são remotos diante da atual legislação, que se orienta pela concepção da competição regulada; contudo, existe um outro risco, ou seja, uma possível mudança das regras em virtude da rapidez do avanço tecnológico, assim como dos contornos políticos estrategicamente elaborados para o setor.

Recebido em 30 de outubro de 2001. Aprovado em 15 de maio de 2002. 
José Eduardo Pereira Filho (eduard_filho@uol.com.br) é Mestre em Ciência Política pelo Programa de Pós-Graduação em Antropologia e Ciência Política da Universidade Federal Fluminense (UFF) e doutorando em Planejamento Urbano e Regional na Universidade Federal do Rio de Janeiro (UFRJ).

\section{REFERÊNCIAS BIBLIOGRÁFICAS}

ALMEIDA, M. H. T. 1996. Pragmatismo por necessidade : os rumos da reforma econômica no Brasil. Dados, Rio de Janeiro, v. 39, n. 2, p. 213-235, abr.-jun.

2001. La política de la privatización de las telecomunicaciones en Brasil. Revista de Economia Política, São Paulo, v. 21, n. 2, t. 82, p. 43-61, abr.-jun.

BANDEIRA, L. A. M. 1997. O governo João Goulart : as lutas sociais no Brasil. Rio de Janeiro : Civilização Brasileira

CAMPOS, R. O. 1994. Lanterna na popa : memórias. Rio de Janeiro : Topbooks.

CARDOSO, F. H. 1990. Perspectivas da socialdemocracia na América Latina, vista do ângulo do Brasil. In : DAVID, M. D. (org.). Socialdemocracia hoje. Rio de Janeiro : Fundação Teotônio Vilela.

CASTRO, A. C. 1995. As empresas estrangeiras no Brasil : 1860-1913. Rio de Janeiro : Jorge Zahar.

COUTINHO, L., CASSiOlato, J. E. \& SILVA, A. N. (orgs.). 1995. Telecomunicações, globalização e competitividade. São Paulo : Papirus.

DINIZ, E. 1998. Globalização, ajuste e reforma do Estado : um balanço da literatura recente. $B I B$ - Revista brasileira de informação bibliográfica em Ciências Sociais. Rio de Janeiro, n.
45, p. 3-24, jan.-jun.

FIORI, J. L. 1991. Democracia e reformas : equívocos, obstáculos e disjuntivas. Texto para discussão n. 262. Rio de Janeiro : Instituto de Pesquisas Econômicas Aplicadas.

1993. Para uma economia do Estado brasileiro. São Paulo : Indicadores de Economia do Setor Público / Fundação para o Desenvolvimento Administrativo, do Governo do Estado de São Paulo.

MELO, M. A. 2000. Política regulatória : uma revisão de literatura. $B I B$ - Revista brasileira de informação bibliográfica em Ciências Sociais, Rio de Janeiro, n. 50, p. 7-43, jul.-dez.

PINHEIRO, P. S. (org.). 1980. O Estado autoritário e os movimentos populares. Rio de Janeiro : Paz e Terra.

OLIVEIRA. E. Q. 1992. Renascem as telecomunicações : construindo a base. São José dos Pinhais : Editel.

PEREIRA FILHO, J. E. 1997. Reforma do Estado e politica de telecomunicações : o impacto das mudanças sobre a Embratel. Niterói. Dissertação (Mestrado em Ciência Política). Instituto de Ciências Humanas e Filosofia, Universidade Federal Fluminense.

VIANA, C. R. 1980. Reforma de base e a política de desenvolvimento : de Getúlio a Jango. Rio de Janeiro : Civilização Brasileira.

\section{OUTRAS FONTES}

ANATEL. 2001. Agência Nacional de Telecomunicações. www.anatel.gov.br : 15.dez.2001.

BRASIL. 1963. Código Brasileiro de Telecomunicações. Decreto n. 52 026, de 20 de maio de 1963, que regulamenta a Lei n. 4117 de 27 de agosto de 1962.

1997. Lei Geral de Telecomunicações. Lei n. 9 472, de 16 de julho de 1997. Dispõe sobre a organização dos serviços de telecomunicações, a criação e funcionamento de um órgão regulador e outros aspectos institucionais, nos termos da Emenda Constitucional n. 8, de 1995. Publicada no Diário Oficial da União de 17 de julho de 1997.

Correio Brasiliense, 24.fev.1988.

Correio da Manhã. São Paulo, 1961-1962. 
EMBRATEL. s/d. Projeto Memória da Embratel. Brasília : Empresa Brasileira de Telecomunicações.

1971. Relatório anual da Embratel. Rio de Janeiro : Empresa Brasileira de Telecomunicações.

1973. Relatório anual da Embratel. Rio de Janeiro : Empresa Brasileira de Telecomunicações.

1980. Telecomunicações para o desenvolvimento. Rio de Janeiro : Empresa Brasileira de Telecomunicações.

1983. Embratel. 18 anos. Rio de Janeiro : Empresa Brasileira de Telecomunicações.

. 1989. Relatório anual da Embratel. Rio de Janeiro : Empresa Brasileira de Telecomunicações.

1996. Relatório da administração da Embratel. Rio de Janeiro : Empresa Brasileira de Telecomunicações.

2002. Empresa Brasileira de Telecomunicações. www.embratel.com.br : 15.maio.2002.
Folha de S. Paulo, 1988-1997.

Gazeta Mercantil. São Paulo, 1988-1997.

Jornal da Embratel. Brasília, jun./jul. 1995.

Jornal do Brasil. Rio de Janeiro, 1962-1997.

Jornal do SINTTEL. Rio de Janeiro, 1985-1998.

Jornal Via Embratel. Brasília, 1980-1997.

Leia e fique sabendo. Brasília, out.1993.

O desafio de 20 anos. Revista nacional de telecomunicações, Brasília, set.1985.

O Diário Carioca. Rio de Janeiro, 06.nov.1960.

O Diário de Notícias. São Paulo, 1960-1962.

O Estado de S. Paulo, 1962-1975.

O Globo. Rio de Janeiro, 1995-1997.

Revista das Classes Produtoras. s/1, 1960-1961.

Revista Via Embratel. Brasília, out.1988.

Sino azul. 1965. Brasília, n. 2.

Telebrasil. Brasília, 1960-1995. 